\title{
EDUCAÇÃO A DISTÂNCIA E OS DESAFIOS PARA A ELABORAÇÃO DE MATERIAL DIDÁTICO DE LÍNGUA PORTUGUESA COMO L2 PARA GRADUANDOS SURDOS
}

\author{
Fernanda Beatriz Caricari de Morais $\left(\right.$ INES) ${ }^{1}$ \\ Osilene Maria de Sá e Silva da Cruz (INES) ${ }^{2}$
}

\begin{abstract}
RESUMO: A Educação à Distância (EaD), baseada numa prática pedagógica mediada pela tecnologia e interatividade, vem passando por constantes evoluções no Brasil no que se refere ao campo tecnológico, educacional e político. O Programa Viver sem Limites/MEC, constituído como parte do Plano Nacional dos Direitos da Pessoa com Deficiência, consiste em uma das formas de possibilitar a plena cidadania das pessoas com deficiência no Brasil, oportunizando direitos, cidadania para todas as pessoas e seu acesso e permanência no ensino superior, na modalidade a distância. Este artigo apresenta uma reflexão sobre os desafios e as possibilidades de elaboração de material didático de Língua Portuguesa escrita para alunos surdos de um curso a distância de Licenciatura em Pedagogia, dentro de um contexto bilíngue de ensino - LIBRAS (L1) e Língua Portuguesa (L2) do Instituto Nacional de Educação de Surdos - INES. Resultados mostram a importância da conscientização do professor conteudista no sentido de preparar material bilíngue, dialógico e interativo que valorize, primeiramente, a L1 do aprendiz, estimulando-o a ler e produzir textos escritos de forma autônoma e autêntica, respeitando-se as estruturas gramaticais da LIBRAS e da LP.
\end{abstract}

PALAVRAS-CHAVE: Educação a distância. Ensino de Língua Portuguesa para surdos. Elaboração de material didático.

\begin{abstract}
The Distance Education, based on a pedagogical practice mediated by technology and interactivity, has been undergoing constant development in Brazil considering technological, educational and political spheres. The Brazilian Program Viver sem Limites/MEC, which is part of the Plano Nacional dos Direitos da Pessoa com Deficiência, consists in a way to implement citizenship to Brazilian people with disabilities, providing rights e citizenship for all people as well as their access and permanence in higher education, in the modality of distance education. This article presents a reflection on the challenges and possibilities of developing didactic materials to teach Portuguese as a second language for Pedagogy deaf undergraduates in a distance learning course, considering mainly the bilingual educational context - LIBRAS (L1) and Portuguese (L2) offered at Instituto Nacional de Educação de Surdos - INES. Results show the importance of the teacher's awareness when preparing bilingual, dialogical and interactive materials, that consider, firstly, the first language of the student, encouraging him to read and produce written texts in an autonomous and authentic way, respecting the grammatical structures of LIBRAS and LP.
\end{abstract}

KEYWORDS: Distance Education. Portuguese teaching to deaf students. didactic material production.

\footnotetext{
${ }^{1}$ Doutora em Linguística Aplicada e Estudos da Linguagem pela Pontifícia Universidade Católica de São Paulo, com estágio doutoral na Universidade de Lisboa. Professora Adjunta no Instituto Nacional de Educação de Surdos (INES/RJ). E-mail: fernandacaricari@gmail.com.

${ }^{2}$ Doutora em Linguística Aplicada e Estudos da Linguagem pela Pontifícia Universidade Católica de São Paulo. Professora Adjunta de Língua Portuguesa como L1 e L2 no Instituto Nacional de Educação de Surdos (INES/RJ) e professora colaboradora do curso de Mestrado Profissional em Diversidade e Inclusão na Universidade Federal Fluminense. E-mail: osilenecruz@gmail.com
} 


\section{$=$ TRAMA $=$}

\section{INTRODUÇÃO}

A Educação a Distância (EaD) é uma das modalidades de ensino do sistema educacional brasileiro, regulamentada pelo decreto 5.622/2005 ${ }^{3}$, em atendimento ao artigo art. 80 da Lei 9.394/1996, que estabelece as diretrizes e bases da educação nacional. Nesse documento, entende-se a EaD como

modalidade educacional na qual a mediação didático-pedagógica nos processos de ensino e aprendizagem ocorre com a utilização de meios e tecnologias de informação e comunicação, com estudantes e professores desenvolvendo atividades educativas em lugares ou tempos diversos (BRASIL, 2005).

No ensino superior, a EaD pode ser ministrada de forma contemplar cursos e programas sequenciais, de graduação, especialização, mestrado e doutorado, mas há que se ter em consideração a relação dialógica entre os participantes dos cursos e os profissionais envolvidos no processo de aprendizagem, tais como o professor conteudista, o professor tutor ou mediador, e, no caso deste artigo sobre elaboração de unidade didática da disciplina de Língua Portuguesa escrita para graduandos surdos, envolve, também, a participação de intérpretes, que possibilitam acessibilidade às leituras e às informações em Língua de Sinais Brasileira (LIBRAS) para os aprendizes surdos.

Este trabalho apresenta uma reflexão sobre os desafios e as expectativas para a elaboração de unidade didática de Língua Portuguesa escrita, na modalidade a distância, para graduandos surdos do curso de Licenciatura em Pedagogia, oferecido pelo Instituto Nacional de Educação de Surdos - INES. O curso faz parte de uma das ações do Programa Viver sem Limites, promovido pelo Governo Federal. Buscamos mostrar a importância do processo de produção de material didático para um curso a distância e os desafios para contemplar uma demanda de alunos que necessitam de estratégias de ensino diferenciadas, de modo que o ensino seja eficiente e promova a permanência desse aluno no curso e sua formação para atuar como profissional na Educação Infantil e nas séries iniciais do Ensino Fundamental.

Para contemplar nossa proposta, seguimos uma concepção bilíngue de ensino, em que as línguas de instrução são a LIBRAS (L1 dos sujeitos surdos) e a Língua Portuguesa na modalidade escrita (L2 desses aprendizes). Na próxima seção, apresentamos uma síntese do histórico da educação de surdos desde os anos de 1750, na França, até os dias atuais no Brasil, em que prevalece a educação bilíngue. O artigo apresenta também informações sobre aspectos legais norteadores do ensino de LIBRAS e de Língua Portuguesa escrita para aprendizes surdos e informações sobre a abordagem teórico-metodológica relacionada à leitura, escrita e ao letramento, utilizados em nossa trajetória didática. Como nosso enfoque é a Licenciatura em Pedagogia bilíngue, ofertado pelo INES, o curso será apresentado e contextualizado.

\section{EDUCAÇÃO DE SURDOS - BREVE HISTÓRICO}

A educação de pessoas com surdez passou por várias fases. Na França, por exemplo, nos anos de 1750, Abade Charles Michel de L'Epée, considerado uma referência na educação de pessoas com surdez, defendia, juntamente com seu seguidor Sicard, o direito à educação pública e gratuita para as pessoas com surdez, independentemente do nível social. O mesmo era defendido por Thomas Hopkins Gallaudet que, em 1817, juntamente com Laurent Clerc,

${ }^{3}$ Acesso ao Decreto 5.622/2005 pelo endereço eletrônico

http://portal.mec.gov.br/sesu/arquivos/pdf/portarias/dec5.622.pdf. Acesso em 15 maio 2014. 
fundou a primeira escola permanente para alunos surdos nos EUA, utilizando a língua de sinais como forma de comunicação. Por outro lado, na mesma época, na Alemanha, predominava o método de ensino oralista, com ênfase no ensino da língua oral e rejeição da língua de sinais. $O$ método oralista foi defendido em 1880 por Alexander Graham Bell, no Congresso Internacional de Educadores de Surdos, realizado em Milão, onde foi colocado em votação, vencendo o método oralista que deveria ser utilizado na educação dos surdos. Nessa época, o uso da língua de sinais foi oficialmente proibido.

No século XX, quase na década de 70, surge a filosofia da Comunicação Total, que utiliza todas as formas de comunicação possíveis na educação das pessoas surdas e, a partir da década de 80 , surge a concepção bilíngue de ensino para surdos, demonstrando que a língua de sinais deveria ser utilizada independentemente da língua oral.

No Brasil, o início da educação de pessoas com surdez teve início em 1857, no atual Instituto Nacional de Educação de Surdos - INES, fundado por Ernest Huet, com o apoio de D. Pedro II. A língua de sinais era utilizada como língua para instrução, comunicação e expressão dos alunos surdos. Por conta da tendência oralista vigente, em 1911, o INES teve que assumir a abordagem oralista, apesar da forte resistência dos alunos que continuavam a utilizar de forma proibida a língua de sinais nos corredores e pátios da escola. No fim da década de setenta, a Comunicação Total chega ao Brasil e, na década seguinte, começa o bilinguismo, que surge com as pesquisas da linguista Lucinda Ferreira Brito, sobre a Língua Brasileira de Sinais.

No contexto brasileiro, presenciamos alguns avanços desde a década de 1980, quando o método bilíngue de ensino passou a predominar para esses aprendizes, considerando-se as formas de expressão do indivíduo surdo por meio da língua de sinais e da língua portuguesa na modalidade escrita.

Vale destacar dois marcos, apresentados na próxima seção, que contribuíram para o avanço na educação de surdos no Brasil: a Lei 10.436/2002 reconhece a Língua Brasileira de Sinais (LIBRAS ${ }^{4}$ como "meio legal de comunicação e expressão" e o Decreto 5.626/2005 regulamenta a lei, estabelecendo, entre outras providências, o ensino de qualidade aos alunos com problemas de audição, a formação e capacitação de professores e de instrutores para o ensino de LIBRAS e de Língua Portuguesa escrita.

\section{ASPECTOS LEGAIS MOTIVADORES - LEI 10.436/2002 E DECRETO 5.626/2005}

A lei 10.436/2002 instituiu a LIBRAS, definindo-a como o "meio legal de comunicação e expressão" de pessoas surdas do Brasil, sendo de natureza visual-motora, com estrutura gramatical própria. Estabelece, no artigo $4^{\circ}$, a inclusão dessa disciplina nos cursos de formação de "(...) Educação Especial, de Fonoaudiologia e de Magistério, em seus níveis médio e superior (...) como parte integrante dos Parâmetros Curriculares Nacionais - PCNs" (BRASIL, 2002).

Vemos essa lei como um avanço político-social, pois reconhece a LIBRAS como língua e como meio de comunicação dentro de uma comunidade de sujeitos surdos e seus interlocutores. Em seu parágrafo único, a lei destaca que essa língua não poderá substituir a modalidade escrita da língua portuguesa.

O decreto 5.626/2005, que regulamenta a referida lei, traz uma série de providências, evidenciando a importância da LIBRAS, do seu uso e da formação de profissionais para atuarem no magistério. A disciplina deve ser parte integrante do currículo obrigatório em todos os cursos de licenciatura, no curso normal de nível médio e no curso normal superior, assim como no curso de Pedagogia e de Educação Especial. Vale ressaltar a atenção que o decreto dedica à

\footnotetext{
${ }^{4}$ Neste artigo, adotamos a sigla LIBRAS como referência à Língua Brasileira de Sinais.
} 
formação de docentes para o ensino de LIBRAS e de Língua Portuguesa como segunda língua, ou seja, na modalidade escrita.

Nesse sentido, verificamos o objetivo do documento para que aluno surdo domine a L1, tendo nela o primeiro e principal instrumento para manifestar seu pensamento e compreensão, e, posteriormente, proceder a produção escrita. Essa ênfase evidencia-se muito claramente quando se trata da formação do docente em Curso de Pedagogia ou Normal Superior, em que a "LIBRAS e a Língua Portuguesa escrita tenham constituído línguas de instrução" e a formação de professores surdos e ouvintes para atuarem na educação infantil e dos anos iniciais do Ensino Fundamental com formação bilíngue - LIBRAS e LP, cursos de Letras/LIBRAS ou Letras/Língua Portuguesa com segunda língua para surdos.

Podemos verificar que o uso e a divulgação da LIBRAS no contexto escolar não excluem o ensino-aprendizagem de Língua Portuguesa, denotando que o ser surdo é, acima de sua condição auditiva, um cidadão brasileiro, oriundo de um país em que a Língua Portuguesa consiste na maioria linguística. Sobre esse tema, o decreto, no artigo 13, estabelece que

o ensino da modalidade escrita da Língua Portuguesa como segunda língua para pessoas surdas, deve ser incluído como disciplina curricular nos cursos de formação de professores para a educação infantil e para os anos iniciais do ensino fundamental, de nível médio e superior, bem como nos cursos de licenciatura em Letras com habilitação em Língua Portuguesa (BRASIL, 2005).

É consenso, na área de educação de surdos, o impacto social causado pelo reconhecimento da LIBRAS como forma de comunicação de um grupo cultural minoritário, pois a surdez, que sempre foi entendida no campo da deficiência, passa a ser reconhecida no campo linguístico cultural.

Ao longo da história, os alunos surdos foram sempre tratados como se fossem ouvintes, ignorados em seu processo de ensino e aprendizagem e, apesar de um movimento positivo nas políticas inclusivas com a oficialização da LIBRAS, a igualdade de direitos ainda não alcançou mudanças concretas nas práticas sociais.

Se a língua de sinais é uma língua natural adquirida de forma espontânea pela pessoa surda em contato com pessoas que usam essa língua e se a língua oral é adquirida de forma sistematizada, então as pessoas surdas têm o direito de ser ensinadas na língua de sinais. A proposta bilíngue busca captar esse direito (MULLER, 1997).

As pessoas ouvintes desenvolvem sua comunicação em contato com outros pares ouvintes pela necessidade natural dos seres humanos de expressarem suas ideias e sentimentos. Essa imersão em um grupo social ouvinte faz com que essas pessoas desenvolvam suas habilidades orais de comunicação. Da mesma maneira, as pessoas surdas têm as mesmas necessidades de expressarem suas ideias e sentimentos. A única diferença é que tais pessoas utilizam o canal espaço-visual como modalidade linguística e não o canal auditivo-oral.

Com o passar do tempo, a LIBRAS tem sido adquirida de forma natural pelas pessoas surdas, demonstrando a capacidade humana para a linguagem. A falta de contato com adultos usuários dessa língua tem dificultado o desenvolvimento de muitas crianças surdas nascidas em famílias de ouvintes, pois a comunicação é precária acarretando prejuízos na aprendizagem.

\section{LIBRAS NO CONTEXTO LINGUÍSTICO EDUCACIONAL}

As línguas de sinais se distinguem das línguas orais porque fazem uso do canal visualespacial e não oral-auditivo. Articulam-se espacialmente e são percebidas visualmente, utilizando o espaço e as dimensões que ele oferece na constituição de seus mecanismos 
fonológicos, morfológicos, sintáticos e semânticos para veicular significados. As línguas de sinais e as línguas orais partilham semelhanças e particularidades, seguindo princípios gerais, usados na geração de estruturas linguísticas de forma produtiva, possibilitando um número infinito de construções a partir de um número finito de regras.

Apesar das diferenças entre as línguas, há também aspectos comuns que interessam às investigações linguísticas (FERREIRA-BRITO, 1995, FELIPE, 1997, QUADROS \& KARNOPP, 2004, entre outros) por explicarem a natureza da linguagem humana. A LIBRAS anula a deficiência e permite que os surdos constituam, então, uma comunidade linguística minoritária diferente e não um desvio da normalidade. É com a LIBRAS que o surdo toma a palavra (SKLIAR, 1999).

Segundo Lacerda e Lodi (2008), as dificuldades encontradas pelas crianças surdas são um reflexo da falta de atendimento às suas necessidades linguísticas e culturais específicas, defasando, assim, o processo de ensino-aprendizagem e dificultando sua inserção social. A educação bilíngue para o surdo é apontada como uma educação que respeita a especificidade linguística permitindo um agir social de forma autônoma.

A pesquisa de Lacerda e Lodi (2008) foi realizada seguindo as orientações da política educacional nacional, conforme a Declaração de Salamanca (1994), que prevê o atendimento de portadores de necessidades especiais nas salas regulares de ensino. Foi proposto pelas autoras um projeto de escolarização às pessoas surdas, contemplando tanto a educação inclusiva quanto a educação bilíngue. A inclusão da criança surda em sala regular de ensino foi questionada pelas autoras desde o princípio por considerarem importante para o desenvolvimento de linguagem um ambiente onde a LIBRAS fosse a língua de instrução e não o português escrito e oral, como ocorre nas classes regulares.

As referidas autoras indicam transformações a serem implantadas para a inclusão bilíngue: a criação de salas cuja língua de instrução seja LIBRAS com professor bilíngue fluente nessa língua, oficinas de LIBRAS para professores e funcionários, aulas de LIBRAS para as crianças ouvintes e oficina de LIBRAS para os alunos surdos, implementando assim seus conhecimentos. Para isso, a presença de um Educador Surdo e de professores preparados é fundamental.

Neste artigo, ao propormos a elaboração de unidades didáticas para ensino de Língua Portuguesa escrita aos graduandos surdos, levamos em consideração a L1 do aprendiz, de modo que todo o material é interativo, dialógico e, mais importante, apresentado em LIBRAS, por intérpretes que facilitam a compreensão dos alunos e a expressão sobre o seu entendimento.

Lima (2004) analisou as práticas de bilinguismo em uma escola da rede pública com proposta de educação inclusiva, discutindo que a educação bilíngue para os alunos surdos possui controvérsias, visto que não explicitam como essa educação se daria na prática, os professores possuem pouco ou nenhum conhecimento da LIBRAS e da educação de surdos, por isso, a importância do Plano Viver sem Limite, apresentado a seguir, com foco na formação de professores.

\section{O LETRAMENTO NO ENSINO DE LÍNGUA PORTUGUESA COMO SEGUNDA LÍNGUA (L2) PARA SURDOS}

O processo de ensino-aprendizagem de Língua Portuguesa como L2 depende do uso de metodologias adequadas que levem em conta as singularidades linguísticas dos surdos. Fernandes (2006), Pereira (2003), Quadros (1997) e Quadros \& Schmiedt (2006) argumentam que muitos aprendizes surdos são filhos de pais ouvintes e tiveram pouco ou nenhum contato com LIBRAS e, por isso, tiveram experiências linguísticas pouco significativas. 
A LIBRAS possibilita a aquisição de conhecimento de mundo, possibilitando a recontextualização do escrito e derivação do sentido. É através da LIBRAS que os aprendizes surdos poderão atribuir sentido ao que leem, deixando de ser meros decodificadores da escrita.

Para Fernandes (2006), baseada em Kleiman (1995) e Soares (1988), o processo de ensino-aprendizagem da leitura e da escrita para surdos é denominado letramento, pois torna esses processos complementares e dependentes, inseridos em práticas sociais significativas. Há diferentes níveis de letramento, dependendo das necessidades do leitor/escritor em seu meio social e cultural.

As práticas de leitura precisam ser contextualizadas, fornecendo condições para que o aprendiz surdo compreenda o texto. O professor deve provocar nos alunos o interesse pela leitura, fazendo discussões prévias sobre o assunto, utilizando estímulos visuais em suas aulas. É preciso pensar nas questões: qual o conhecimento que os alunos têm da temática abordada no texto? Como esse conhecimento pode ser explorado em sala de aula na apresentação do texto? Quais são as palavras fundamentais para a compreensão? Quais elementos linguísticos podem favorecer a compreensão? É a medida que o aprendiz compreende os textos que ele começa a produzi-los.

O letramento de surdos enquanto processo faz sentido se significado por meio da LIBRAS, língua usada na escola para aquisição da Língua Portuguesa (L2) na forma escrita que tem suas funções sociais representadas no contexto brasileiro.

Para Lodi et. al (2002), ser letrado é participar ativamente de práticas discursivas letradas a partir de diversos materiais de circulação social propiciados pelas agências de letramento. A autora ainda critica as práticas escolares desvinculadas do contexto social, a supervalorização da Língua Portuguesa e a descaracterização da gramática da LIBRAS.

A aprendizagem da escrita deve ser relativizada e pensada segundo as necessidades e particularidades de cada grupo social. É importante buscar a compreensão a partir da história de vida dos conhecimentos de mundo já aprendidos pelos alunos.

Fernandes (2003), em sua tese, propõe três eixos de trabalho com a linguagem escrita para aprendizes surdos: 1) funcional; 2) lexical (vocabulário) e 3) gramatical (forma e estrutura), sendo que a base desse trabalho é a língua materna (LIBRAS). Os aspectos funcionais estão relacionados à função social do texto (participantes, intenção, veículo de circulação, gênero textual). Enquanto os aspectos lexicais se referem às palavras que só adquirem significados no contexto em que estão veiculadas, por isso, há necessidade de sistematização do vocabulário (léxico) implicado no texto e sua intertextualidade com leituras anteriores. O último eixo, aspectos gramaticais, está relacionado com as regras de organização da língua que permitem que seus usuários se entendam entre si, sendo que aprender uma língua envolve conhecer a sua gramática. As regras gramaticais não são externas ao texto, mas são constituídas internamente. O foco não é a gramática tradicional, mas o uso da língua.

Ler envolve a compreensão global do texto, situando em determinada realidade social, fazendo parte de determinado gênero discursivo e atribuindo relações e efeitos de sentido entre as unidades que o compõe.

Baseadas nessa proposta de Fernandes (2003), também colocamos em nosso curso a leitura de textos na centralidade das práticas de letramento em sala de aula, seja em contexto presencial, seja à distância. Tendo cuidado para a seleção de textos que deve levar em conta os assuntos que sejam de interesse do aluno, tenham abrangência social. Quanto maior o contexto de circulação, maiores serão as possibilidades de que ele seja familiar ao aluno, permitindo-o fazer associações com seu conhecimento prévio que é o que facilitará ou dificultará a mediação do professor na exploração do texto. 
As práticas com texto mostram a relação entre língua e cultura em diferentes variantes e gêneros discursivos, propondo um roteiro de leitura, com levantamento de hipóteses sobre a compreensão, a contextualização visual, exploração do conhecimento prévio e identificação de elementos textuais e paratextuais, discussão das hipóteses, leitura individual e (re) elaboração escrita com vistas à sistematização.

A leitura e a escrita são processos indissociáveis. Não há proposta de produção de texto se o tema não for trabalhado anteriormente em atividades de leituras anteriores, pois estas potencializam a produção escrita pelo aprendiz. É possível enriquecer a leitura expondo os aprendizes à outros textos, oportunizando novas leituras para ampliar a cultura do escrito e os pontos de vista sobre diferentes temas. O trabalho com textos deve ser contextualizado, isto é, partir de uma atividade significativa para o aluno. Atividades de produção escrita que permitem utilizar o conhecimento sistematizado, criando textos nos gêneros propostos.

É importante lembrar que aprender uma língua não é somente aprender outro sistema, nem passar informações a um interlocutor, mas construir no discurso (a partir de contextos sociais concretos e experiências prévias) ações sociais e culturais apropriadas (Almeida Filho, 1990).

\section{O PLANO VIVER SEM LIMITES}

No ano de 2011, o Governo Federal lançou o Viver sem Limite ${ }^{5}$, um Plano Nacional dos Direitos da Pessoa com Deficiência, como resultado do firme compromisso político com a plena cidadania das pessoas com deficiência no Brasil, oportunizando direitos e cidadania para todas as pessoas. Ao lançar essa iniciativa, busca-se uma sociedade mais justa e plural para todos os brasileiros, especialmente aqueles que possuem alguma deficiência, o que representa 23,91\% da população, cerca de 45,6 milhões de pessoas, como mostra o Censo 2010.

Segundo a proposta desse plano, só serão produzidas mudanças para a superação de limites quando equipararmos oportunidades entre pessoas com e sem deficiência, visto que os limites não são definidos pela condição de cada pessoa, mas pela sociedade, seja através de obstáculos físicos ou de atitudes preconceituosas.

Sabe-se que o acesso à educação é direito de todos, sem discriminação, em igualdade de oportunidades. Com base nessa afirmação, o plano Viver sem Limite investe em recursos e serviços de apoio à educação básica, por meio de implementação de salas de recursos multifuncionais, promoção de acessibilidade nas escolas, aquisição de materiais e a formação de professores. Este último investimento conta com a parceria do Instituto Nacional de Educação de Surdos (INES) que é responsável pela oferta do curso Pedagogia na perspectiva bilíngue (LIBRAS/Língua Portuguesa).

Para tornar realidade a educação bilíngue no Brasil, o Viver sem Limite prevê a criação de 27 cursos de Letras/LIBRAS - Licenciatura e Bacharelado e 12 cursos de Pedagogia Bilíngue, sendo criadas, por meio desse plano, 690 vagas para que as instituições federais de educação contratem professores, tradutores e intérpretes de LIBRAS.

O INES participa do programa Viver se Limites, apresentado a seguir, oferecendo o curso de Licenciatura em Pedagogia bilíngue, para alunos surdos e ouvintes, e as línguas de instrução são a LIBRAS e a Língua Portuguesa.

\section{O CURSO DE PEDAGOGIA DO INSTITUTO NACIONAL DE EDUCAÇÃO DE SURDOS (INES)}

O Plano Viver sem Limite possibilitou mudanças importantes, em especial para a educação de surdos, pois valoriza o uso da LIBRAS no ambiente educacional, busca a

\footnotetext{
${ }^{5}$ O Plano Viver sem Limites foi regulamentado pelo decreto 7.612/2011, disponível no endereço eletrônico: http://www.planalto.gov.br/ccivil 03/ Ato2011-2014/2011/Decreto/D7612.ht. Acesso em 24 jun 2015.
} 


\section{$=$ TRAMA $=$}

qualificação de professores para o ensino bilíngue e adaptações curriculares que tornem possível a inclusão do surdo na escola regular.

É importante destacar que desde 2004, o INES desenvolve ações para a implementação de curso superior de Pedagogia Bilíngue - Licenciatura Plena, que teve início presencialmente em 2006, no próprio INES, na cidade do Rio de Janeiro-RJ.

Para atender uma demanda nacional, parte dos objetivos do Plano, o INES criou o curso de Pedagogia Bilíngue na modalidade online, em parceria com 12 instituições federais (Institutos e Universidades), abrangendo as cinco macrorregiões do Brasil.

Figura 1: Mapa do Brasil com os pólos do curso Pedagogia Bilíngue.

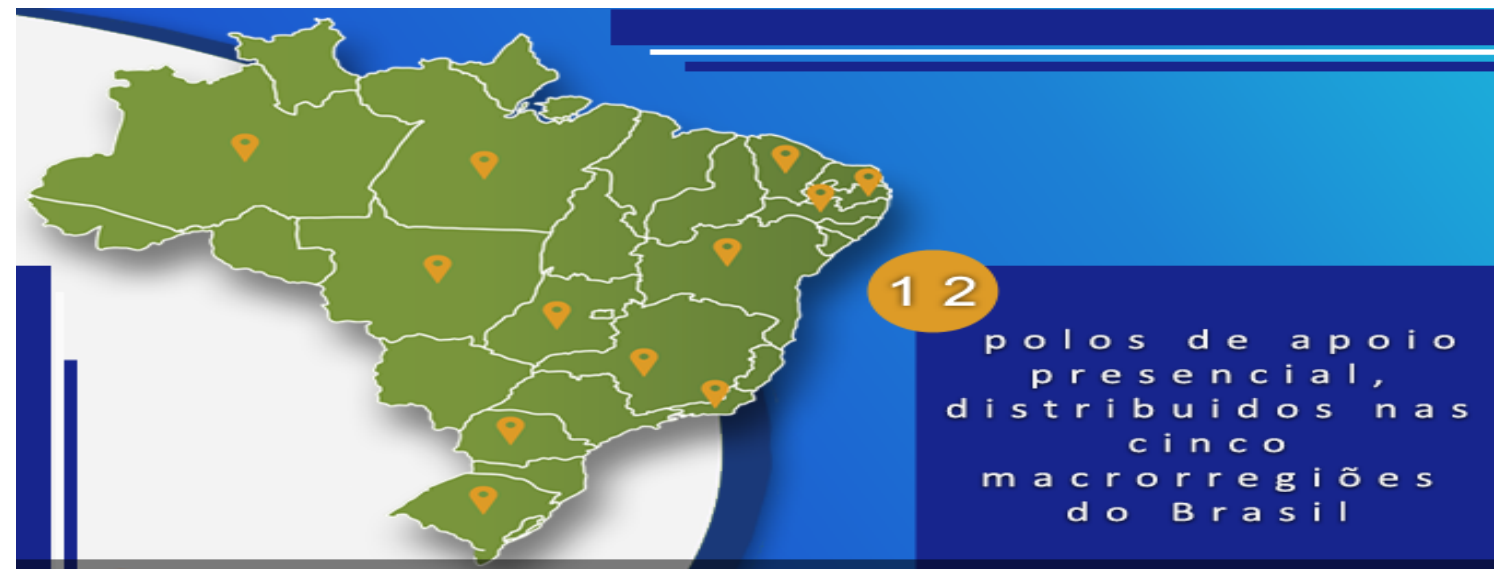

- INES - Instituto Nacional de Educação de Surdos

- UFAM - Universidade Federal do Amazonas

- UFC - Universidade Federal do Ceará

- UEPA - Universidade Estadual do Pará

- IFPE - Instituto Federal de Pernambuco

- UFPB - Universidade Federal da Paraíba

- UFBA - Universidade Federal da Bahia

- IFG - Instituto Federal de Goiás

- UFGD - Universidade Federal de Grande Dourados

- UFLA - Universidade Federal de Lavras

- UFPR - Universidade Federal do Paraná

- UFRGS - Universidade Federal do Rio Grande do Sul

Os conteudistas são os professores adjuntos no INES que buscam desenvolver uma metodologia própria para o público do curso (surdos e ouvintes), utilizando o que há de mais atual no desenvolvimento de cursos online, em parceria com a comunidade surda para o desenvolvimento de uma formação pioneira e que leve em conta os anseios dos alunos surdos.

Experiências com o público surdo no curso de extensão Compreensão e Produção em Língua Portuguesa como L2 para surdos, desenvolvido desde 2014 e a criação do Projeto de pesquisa Ensino de línguas e literaturas no ensino bilíngue de surdos, cadastrado no CNPq, possibilitaram a reflexão e a elaboração de materiais com foco nesses aprendizes.

Pensando nessas questões o Ambiente Virtual de Aprendizagem, o AVA, será customizado para atender às necessidades e às exigências do público-alvo contemplado pelo curso de Pedagogia Bilíngue, dando suporte a animações, vídeos, jogos, chats, fóruns e 
avatares, permitindo aos professores conteudistas muitas possibilidades para atender os aprendizes usuários de Língua Portuguesa e de LIBRAS.

O quadro a seguir apresenta os recursos disponíveis na plataforma, segundo o manual do professor-conteudista (INES, 2016, p. 12-14).

Quadro 1: recursos disponíveis na plataforma do curso online.

\begin{tabular}{|c|c|}
\hline Recursos disponíveis & Síntese \\
\hline Chats & $\begin{array}{l}\text { as conhecidas salas de bate-papo, em que os } \\
\text { atores do processo poderão se comunicar ao } \\
\text { longo do curso. Obviamente haverá a opção de } \\
\text { chamadas por meio de vídeos }\end{array}$ \\
\hline Fóruns & $\begin{array}{l}\text { tópicos de discussões orientadas, em que serão } \\
\text { propostas atividades a serem cumpridas. Nesta } \\
\text { ferramenta, também teremos a possibilidade de } \\
\text { postagem de vídeos em LIBRAS, língua com a } \\
\text { qual muitos de nossos alunos se sentem mais à } \\
\text { vontade }\end{array}$ \\
\hline Mapa mental & $\begin{array}{l}\text { uma rede de mapas conceituais, em que os } \\
\text { alunos e os professores desenvolverão de forma } \\
\text { dinâmica todos os conteúdos trabalhados em } \\
\text { cada unidade } 12 \text { do curso }\end{array}$ \\
\hline $\begin{array}{l}\text { PLE (Personal Learning Environment - Ambiente } \\
\text { pessoal de aprendizagem) }\end{array}$ & $\begin{array}{l}\text { uma rede social própria, em que cada aluno será } \\
\text { responsável por publicar conteúdos que } \\
\text { agreguem valor ao material trabalhado em cada } \\
\text { disciplina, trazendo informações e discussões } \\
\text { próprias e criando uma grande rede de } \\
\text { aprendizagem com outros alunos e professores, } \\
\text { de dentro e de fora do curso. }\end{array}$ \\
\hline
\end{tabular}

É importante mencionar que cada disciplina conta com dois professores-mediadores, sendo um pedagogo e um professor de LIBRAS, que recebem as informações técnicas e teóricas de modo a conduzirem o curso, em contato sempre que necessário com o professorautor da disciplina. Os professores possuem ainda o suporte de desenhistas instrucionais e webdesigners, parceiros na montagem e no desenvolvimento do curso, além de toda uma equipe técnica responsável pela manutenção do curso.

A avaliação dos alunos ocorre na modalidade on-line e presencial, sendo a presencial realizada no polo onde o curso é oferecido e ocorre ao longo da disciplina. Ao longo de cada unidade, o professor-mediador verifica se o aluno atingiu os objetivos previstos dentro do conteúdo trabalhado. Essa avaliação é definida pelo professor-autor e pode ser uma prova escrita, um trabalho em grupo, uma pesquisa ou outra estratégia que o professor preferir.

O material proposto pelos professores-autores é trabalhado e acompanhado por desenhistas instrucionais (DIs) que fazem parte da equipe e são responsáveis por moldar cada disciplina. A linguagem é um importante recurso que deve atingir o aluno de uma forma ao mesmo tempo amigável, estimuladora e respeitosa, tornando a aprendizagem uma experiência agradável e eficaz dentro das propostas desenvolvidas no curso.

Há de se atentar para a utilização da linguagem não verbal utilizada de forma bastante intensa, explorando essa variedade comunicativa, pois se trata de um curso bilíngue, o que exige um foco no visual, no imagético. 


\section{$=$ TRAMA $=$}

\section{PROCEDIMENTOS NA ELABORAÇÃO DAS UNIDADES DIDÁTICAS}

Como já explicitado na seção anterior, o curso de Pedagogia na modalidade a distância oferece a disciplina de Língua Portuguesa em quatro períodos (LP I a LP IV), sendo o material didático elaborado diferentemente para os alunos ouvintes e para os alunos surdos, com o objetivo de contemplar as necessidades dos respectivos alunos, principalmente, de oferecer aos participantes surdos o acesso à LP por meio da LIBRAS, ou seja, todo o material a ser ensinado com conteúdo de LP é interpretado em LIBRAS, estimulando a compreensão e a expressão na L1 do aprendiz.

O curso também contém também as disciplinas: Metodologia do ensino de LP, Alfabetização e Letramento e de Literatura e formação do leitor, contemplando, dessa forma, um currículo adequado para que o futuro profissional seja capaz de aperfeiçoar seus conhecimentos de LP e também agregar conhecimentos para o ensino de LP em sua atuação profissional.

Com relação à disciplina de LP, que é o foco deste artigo, existe uma preocupação em construir ambiente dialógico com os participantes do curso, seguindo os pressupostos de Bakthin (1992), de modo que o aluno não sinta em um ambiente unilateral em que as informações são "postadas" e cobradas sem que ele seja participante do processo. Somam-se a isso a preocupação na seleção dos textos, de forma que sejam provocativos, estimuladores de respostas e de interações entre os alunos, alunos e professores (tutor e conteudista), dentro de uma perspectiva dialógica. Seguimos o que está proposto no decreto 5.626/2005, no sentido de valorizar a L1 dos aprendizes para o ensino da L2.

Mais especificamente, cada disciplina é constituída por sete (07) unidades didáticas, que seguem as ementas definidas pelo grupo de professores de LP e que foram aprovadas pelo Núcleo Docente Estruturante (NDE) do INES. As unidades didáticas são postadas no site do curso e são constituídas, fundamentalmente, por:

$>$ Um roteiro de apresentação - contém as informações iniciais sobre o que será estudado na unidade. Esse roteiro é elaborado em língua portuguesa e interpretado em LIBRAS, trazendo cenas e imagens instigadoras.

$>$ Dois textos (texto 1 e texto 2) sobre o conteúdo seguidos por perguntas interativas - o objetivo é gerar debates entre os alunos e entre os alunos e professores. Esse debate é promovido em LIBRAS e, em um segundo momento, é estimulada a produção escrita.

$>$ Três objetivos que devem ser atingidos pelos alunos - esses objetivos devem contemplar o conteúdo da unidade.

$>$ Três temas para chats - o contexto das unidades é interativo e dialógico, por isso, os temas para os chats devem ser provocativos, sobre o conteúdo da unidade como um todo.

$>$ Nove endereços eletrônicos (sites) para consulta do conteúdo e que serão utilizados pelo professor mediador para esclarecer dúvidas e expandir os temas propostos nos textos $1 \mathrm{e}$ 2.

$>$ Um vídeo de aproximadamente 2 minutos contendo informações sobre o tema da unidade - o vídeo é outra forma de contemplar a necessidade do aprendiz, pois é apresentado em LIBRAS e é sucinto, com as principais informações da unidade.

$>$ Um resumo complementar - o resumo traz um apanhado geral de todo o conteúdo teórico abordado na unidade, como uma fonte adicional a ser utilizado pelo aluno.

> Atividade para trabalho em grupo - o professor conteudista deve elaborar, no mínimo, 4 trabalhos a serem realizados em grupos em dias de sábado, sendo acompanhado pelo professor mediador.

> Glossário - termos, expressões e conceitos utilizados na unidade, que são explicados no glossário para facilitar o entendimento e ampliar o conhecimento do aluno. 
Ao elaborarmos as unidades didáticas, temos como primeiro desafio trabalhar com o conhecimento do aluno com relação à Língua Portuguesa. Nossa experiência no curso presencial e nos cursos de extensão oferecidos a alunos surdos, assim como nossos estudos no grupo de pesquisa mostra que os alunos têm muitas dificuldades com a língua escrita, demandando dos professores, primeiramente, quebrar uma barreira com relação à importância da LP na sociedade brasileira e mundial, pois muitos alunos argumentam que a LIBRAS é a L1 e que eles têm direito à comunicação nessa língua. Um dos argumentos a que recorremos é a importância da LP no mercado de trabalho e a que a prática da leitura e da escrita corretamente faz com que o indivíduo ultrapasse muitas limitações na sociedade. Como exemplo, destacamos a importância da identificação e da elaboração de determinados gêneros textuais, como o currículo vitae, formulário de inscrição em cursos, fichas de ofertas de emprego, cartas pessoais e profissionais, etc.

Assim sendo, os conteúdos são trabalhados em textos mais curtos, provocativos, com vocabulário acessível e o glossário traz significados de palavras e expressões menos comuns aos surdos e definições importantes. As perguntas ao final de cada texto são construídas dialogicamente e são direcionadas ao aluno em LIBRAS, de modo que o aprendiz seja desafiado a dialogar, interagir com os colegas e com os professores. Vale destacar que a produção escrita é a última fase do processo de ensino-aprendizagem de Língua Portuguesa escrita.

Não podemos ignorar os recursos visuais, associados às características linguísticas e estruturais nos textos. Dessa forma, os textos e as explicações trazem imagens, fotos, ilustrações com explicações detalhadas e instigadoras, estimulando o aluno a apreender a informação e praticá-la de forma consciente e autônoma.

Tendo em vista as considerações sobre elaboração de unidade didática para um curso de graduação a distância, cujo público-alvo é formado por surdos e ouvintes, consideramos muito importante o cuidado e o conhecimento, principalmente, do aluno surdo quando da elaboração desse material didático, em que a LIBRAS seja a língua predominante, em que os recursos visuais, verbais e não verbais sejam bem selecionados e abordados para que o ensino seja eficaz.

\section{CONSIDERAÇÕES FINAIS}

Este artigo buscou mostrar o processo de elaboração do material online do curso de Pedagogia Bilíngue, com foco nas disciplinas de Língua Portuguesa (LP), apresentando os recursos disponíveis, os desafios da modalidade EaD e o trabalho com a leitura e a escrita com aprendizes surdos que demandam uma visão de língua vivenciada por práticas concretas.

Com base nos pressupostos teóricos dos estudos sobre ensino de LP como L2 para surdos, as propostas de atividade propiciam a reconstrução do texto, partindo de sua realidade visual e do conhecimento prévio que esses aprendizes têm sobre a língua alvo (LP). Sempre procuramos despertar o interesse desses alunos na leitura para se distrair, se informar e se tornar cidadãos conscientes de seus direitos e deveres.

É importante destacar que temos uma preocupação constante em revisar as unidades propostas e acompanhar os tutores na interação com os alunos no ambiente virtual, refletindo a eficácia e as dificuldades operacionais encontradas.

Com relação a preocupação com a formação do professor, temos a preocupação de oferecer um curso a distância com foco na prática de leitura e escrita, colocando os alunos em práticas reais de letramento, valorizando a cultura surda, a LIBRAS e a bagagem cultural de cada indivíduo. 
Como estudos futuros, pretendemos analisar as unidades didáticas e as produções textuais dos alunos surdos, descrevendo as escolhas léxico-gramaticais na língua alvo e a influência da língua materna (LIBRAS) em situações de interlíngua.

\section{REFERÊNCIAS}

ALMEIDA-FILHO, J. C. P. Identidades e caminhos no ensino de Português para estrangeiros. Campinas: Ed. UNICAMP, 1992.

BAKHTIN, M. Estética da criação verbal. São Paulo: Martins Fontes, 1992.

BRASIL.Lei no 10.436, de 24 de abril de 2002. Dispõe sobre a Língua Brasileira de Sinais - LIBRAS e dá outras providências. Disponível em:<http:www.planalto.gov.br> Acesso em: 07.01.2015.

BRASIL.Congresso Nacional. Lei de Diretrizes e Bases da Educação (Lei 9.394/96). Brasilia, Centro Gráfico, 1996.

BRASIL. Decreto N ${ }^{\circ}$ 5.626. Regulamenta a Lei $n^{\circ} 10.436$, de 24 de abril de 2002, que dispõe sobre a Língua Brasileira de Sinais - LIBRAS, e o art. 18 da Lei n 10.098, de 19 de dezembro de 2000. Publicada no Diário Oficial da União em 22/12/2005.

FELIPE, T. A. Introdução à gramática de LIBRAS. Rio de Janeiro: FENEIS, 1997.

FERNANDES, S. Educação bilíngue para surdos: identidades, diferenças, contradições e mistérios. Curitiba, 2003. Tese (Doutorado em Letras), Universidade Federal do Paraná.

FERNANDES, S. Práticas de letramento na educação bilíngue para surdos. Curitiba: SEED/SUED/DEE, 2006. FERREIRA-BRITO, L. Por uma gramática da língua de sinais. Rio de Janeiro: Tempo Brasileiro, 1995.

LACERDA, C. B.F.,LODI, A. C. B. A difícil tarefa de promover uma inclusão escolar bilíngue para alunos surdos. GTEducação Especialn.15 Anped, 2008.

LIMA, M S. C. Surdez, bilinguismo e inclusão: Entre o dito, o pretendido e o feito. Tese de doutorado -

Unicamp, Campinas. 2004

LODI, A.C.B. HARRISON, K.M.P.; CAMPOS, S.R.L. Leitura e escrita no contexto da diversidade. Porto Alegre: Editora Mediação, 2002.

LODI, A.C.B.; LACERDA, C.B.F. Uma escola, duas línguas: letramento em língua portuguesa e língua de sinais nas etapas iniciais de escolarização. Porto Alegre: Editora Mediação, 2008.

KLEIMAN, A. B. (org.) Os significados do letramento: uma nova perspectiva sobre a prática social da escrita. Campinas : Mercado de Letras, 1995.

INSTITUTO NACIONAL DE EDUCAÇÃO DE SURDOS. Manual do Professor-autor. Rio de Janeiro: INES, 2016.

MULLER, C. R. Professor surdo no Ensino Superior: Representações da prática docente. Dissertação de Mestrado - UFSM, Santa Maria, RS. 2009.

PEREIRA,M.C.C. Papel da língua de sinais na aquisição da escrita por estudantes surdos. In: LODI, A.C.B.; HARRISON, K.M.P.; CAMPOS, S.R.L.; TESKE, O Letramento e minorias. Porto Alegre: Editora Mediação, 2002.

PEREIRA,M.C.C. Leitura, escrita e surdez. São Paulo: Secretaria de Educação do Estado de São Paulo, 2003. QUADROS, R. M. Educação de surdos: a aquisição da linguagem. Porto Alegre: Artmed,1997.

QUADROS, R. M. de; KARNOP, L. Língua de sinais brasileira: Estudos linguísticos. ArtMed. Porto Alegre. 2004.

QUADROS, R. M., SCHMIEDT, M. L. P. Ideias para ensinar português para alunos surdos. Brasília: MEC, SEESP, 2006.

SALAMANCA, Declaração. Sobre Princípios, Políticas e Práticas na Área das Necessidades Educativas

Especiais. Disponivel em: <http: portal.mec.gov.br seesparqiuivospdfsalamancapdf> Acesso em 07.01.2015.

SKLIAR, C. Bilinguismo e biculturalismo: Uma Análise sobre as narrativas tradicionais na educaçãa dos surdos. Revista Brasileira de Educação Nº, Mai/Jun/Jul/Ago 1999.

SOARES, M. B. Letramento: um tema em três gêneros. Belo Horizonte: Autêntica, 1988. 